\title{
UNIVERSITY OF CALIFORNIA.
}

\section{AGRICULTURAL EXPERIMENT STATION.}

BULLETIN No. 73 .

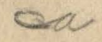

\section{The Use of Hydrocyanic Acid Against Scale Insects.}

Note.-As stated in a previous University Bulletin (No, 7r, June 12,1887 ), a special investigation was undertaken by this station at the request of orange-growers of San Gabriel, Los Angeles county, to determine the practicability and efficiency of gaseous insecticides. The results obtained were so satisfactory that ' the orange-growers who bore the extra expenses of the first experiments urged the advantages of continuing the work, and the Brard of Supervisors made an appropriation to cover expenses, the work to be done under the auspices of the County Horticultural Commissioners. For this reason the following description of later experiments and their results takes the form of a report to the local authorities of Los Angeles county.

To the Board of Horticultural Commission. ers of Los Angeles County-Gentuemen : I herewith transmit a preliminary report of investigations, carried on at your request, relating to the use of gas as an insecticide against the cottony cushion scale insect (Icerya pur chasi). The work was a continuation of that carried on some time ago, and consists mainly in devising means for the easier application of the gas which was found by the earlier experi ments to be the most $e$ fficient.

In resuming the work, to carry out the general principles of application as set forth in the last report, it was found necessary to vary considerably the form of apparatus and prelim. inary preparation of materials, for the purpose of increasing the rapidity and certainty of application. A fan-blower capable of carrying a heavy volume of wind replaced the pump previ ously used, and this necessitated a change in the form of the generator.

Miny experiments were made to determine the most convenient methods for using the chemicals. The old way of mixing the soda and cyanide in the generator was found to be too slow and uncertain to be practicable. Often a heavy crystalline coating formed around the mixture and prevented complete action when the acid was added; again, when the two salts were not mixed, the usefulness of the carbonate as a protection to the foliage was often lessened. In order to avoid this difficulty, it became necessary to reverse the order of application and inject slowly the salt mixture upon the acid, as given in the directions below.

A a attempt was made to use each ingredient separately, the soda being in a solid form, but the same difficulties of uncertainty and slow. ness were experienced.
The generutor, in general terms, consists of a sheet-iron cylinder, or tank, held between two pieces of plank, one of which forms the cover, and the other a movable base which is carried up and down by an eccentric placed be neath. The cover holds two receivers (one for the acid and one for the cyanide and soda) and two tubes opening into the exit pipe which passes over the generator from the blower. A heavy volume of air, carrying with it the gas, is forced by the blower into the tent through a $3 \frac{1}{2}$-inch pipe, and after diffusing is again carried back by a similar pipe to the blower, thus es tablishing a continuous circulation and stirring up of the gas during the treatment.

In the pipes leading to and from the tent are two joints-one at the elbow close to the generator, used as a disconnecting joint when the apparatus is moved; the other, about three feet from this point, is used as the disconnecting joint when two tents are worked with the same generator, and becomes only a flexible joint when one tent is used; the former in this case becomes the disconnecting joint. The opening of the injecting pipe is covered with a perforated cap which distributes the gas when pumped into the tent.

The tent for covering the tree is made of heavy bed-ticking, thoroughly oiled with lin. seed oil. This cloth serves the purpose best, as it is very closely woven, is pliable and easily folded. Practice has shown that much labor and time can be saved, and less injury done to the tree, by having a tent which passes easily over the tree, with cloth enough to make a close connection at the bottom with the earth. The cloth is folded out at the bottom rather than folded in, as in the older treatments, and its margin covered with dirt, thus increasing the area of soil treated without materially increasing the volume within which is to be filled with gas.

The tent should be made somewhat bellshaped, having a "flange" at the bottom of sufficient size to move outside of the main tent at all times, and should fold over like a glove when the tent is removed. It should also be large, so that the points of attachment of the aide guy ropes may be drawn close to the pulleys in the corners of the frame; thus, when wide spreading trees are to be treated, the tent can easily be drawn over any branches included within the frame.

"The support of the tent, devised by Mr. Titus, is a very ingeniously contrived scaffolding mounted on wheels, which serve to move it from one tree to another. Its dimensions are 
26 feet high, with a base $20 \times 20$ feet. Its upper part is $20 \times 12$, and carries upon the top a roller made of gaivanized iron $(6$ inches in diameter and 12 feet long), upon which the tent is rolled when taken from the tree. Side guy-ropes are attached to the bottom of the tent and run through pulleys at the upper corners of the scatfold. They are used to open the tent when it is to ba dropped over the tree, and to fold it up when it is removed. The lightness of the apparatus allows of it being easily removed by two men, who operate the whole. If necessary, two or more tents can be handled by the same soaffolding, one tent being left over the tree while tile ecaffolding is moved to the next."

Later experience shows that it is advantageous to have a frame for each tent, with one generator to supp'y the gas for two tents. Such an arrangement can be handled by one crew of men without loss of time.

Acit.-Much of the success of the operation depends upon the use of acid of the proper strength, and it should be specially urged that the acid be of the strength recommended in the table of doses given below. This any workman can determine by the use of a $B$ iu ne hydrom. eter, which can easily be procured with sufficient instructions for its use. If the acid is not of the proper strength, the table below will show the amounts to be used corresponding to the degrees indicatel by the hydrometer. Thus, if the acid only shows $50^{\circ}$, use the col umn marked $50^{\circ}$ Baume in place of that of the $65^{\circ}$ in the regular prescribed doses of acid.

\begin{tabular}{|c|c|c|c|c|}
\hline $\begin{array}{l}\text { Size of Tree. } \\
\text { Feet. }\end{array}$ & $\begin{array}{c}65^{\circ} \\
\text { Baume. }\end{array}$ & $\begin{array}{c}63^{\circ} \\
\text { Baume. }\end{array}$ & $\begin{array}{c}55^{\circ} \\
\text { Bume. }\end{array}$ & $\begin{array}{c}50^{\circ} \\
\text { Baume. }\end{array}$ \\
\hline 5 & .9 & I. I & I. 2 & I. 3 \\
\hline 6 & x. 6 & I. 8 & $2 I$ & 2.3 \\
\hline 7 & 26 & 29 & $3 \cdot 3$ & 3.7 \\
\hline 8 & $\begin{array}{l}3,8 \\
5,5\end{array}$ & $\begin{array}{l}4 \cdot 3 \\
6.2\end{array}$ & $\begin{array}{l}4.9 \\
7.0\end{array}$ & $5 \cdot 5$ \\
\hline 10 & 75 & 8.5 & 96 & 10.7 \\
\hline II & 99 & I I. 3 & 127 & 14.2 \\
\hline 12 & 12.9 & 147 & 16.5 & 18.4 \\
\hline$I_{3}$ & 16.5 & 18.8 & $2 \mathrm{r} \cdot \mathrm{I}$ & 23.6 \\
\hline 14 & 20.5 & 233 & 26.2 & 29.3 \\
\hline 15 & $25 \cdot 3$ & 28.8 & 32.4 & $3^{6.2}$ \\
\hline 16 & $3^{\circ} .7$ & 35.0 & 393 & 42.9 \\
\hline 17 & 37.8 & 430 & $4^{8} 4$ & 54.0 \\
\hline 18 & 437 & 49.8 & 559 & 62.5 \\
\hline 19 & $51 \cdot 3$ & 58.4 & 65.6 & 73.4 \\
\hline 20 & 60.0 & 68.4 & 76.8 & 85.8 \\
\hline
\end{tabular}

Soda - It is best to use the bi carbonate instead of the neutral carbonate of eoda. It should be finely pulverized, and can be con. veniently measured in a can which will hold ore pcund and fractions of a pound.

Solutions.-The cyanide of potassium solution (not the "mining cyanide") is prepared by dis. solving the salt in the proportion of ten pounds to two gallons of water. Place the cyanide in the vessel in which you wish to make the soln. tion and add the water to it, bring nearly to boiling with occasional stirring, and let it cool. It is best to make the solution one or two days before using, in order to avoid as much as possible the stronger odor of a freshly prepared solution.
In the prescribed dose an excess of acid has been recommended, in order that complete action shall always take place. It is desirable to test the residue occasionally to be satisfied that the work is complete. This is done by adding a little more acid and noting whether boiling or effervescence takes place upon stirring; care being taken not to mistake the effervescence from the material accidentally gathered on the sides of the cylinder during the operation, for that of material which should have been acted upon in the bottom of the cylinder.

\section{Doses According to Size of Tree.}

The regulation of the doses for the different siz 3 drees 80 as to produce uniform treatments is calculated on the basis of the results of the experiments which determined the amount of each constituent for a 12 -foot tree. The follow. ing table indicates the amounts for trees of dif. ferent dimensions of top, based upon the rates of cubical contents.

The amount of material for each dose differs from that previously recommended (Bulletin 71) by a decrease of one-fourth in the amount of soda and a slight change in the acid; the cyanide remains the same. Varying amounts of soda were used showing quite clearly that a decrease of one-fourth was possible, but farther than this an appreciable lessening in the preservative effect was noticeable.

\begin{tabular}{|c|c|c|c|}
\hline $\begin{array}{c}\text { Size of } \\
\text { Tree. }\end{array}$ & $\begin{array}{l}\text { Cyanide of } \\
\text { Potassium. }\end{array}$ & $\begin{array}{c}\text { Bi-carbonate } \\
\text { of Soda. }\end{array}$ & $\begin{array}{l}\text { Sulphuric } \\
\text { Acid. }\end{array}$ \\
\hline $\begin{array}{c}\text { Feet. } \\
5\end{array}$ & $\begin{array}{c}\text { Fluid ozs. } \\
\text { I } 6\end{array}$ & $\begin{array}{c}\text { Pounds. } \\
\qquad x\end{array}$ & $\begin{array}{c}\text { Fluid ozs. } \\
.9\end{array}$ \\
\hline 6 & 2.5 & .2 & I. 6 \\
\hline 7 & 40 & $\cdot 3$ & 2.6 \\
\hline 8 & 6.0 & .4 & 3.8 \\
\hline 9 & 85 & .5 & 5.5 \\
\hline xo & It. 5 & .7 & 7.5 \\
\hline I I & 15.5 & .9 & 9.9. \\
\hline I2 & 20.0 & I. I & 129 \\
\hline I3 & 25.4 & 1.5 & I6. 5 \\
\hline 14 & 31.6 & I. 9 & 20.5 \\
\hline 15 & 39.2 & 2.2 & 25.3 \\
\hline 16 & 47.5 & 2.6 & 30.7 \\
\hline I7 & 57.5 & 3. I & 37.8 \\
\hline 18 & 67.7 & 3.8 & 43.7 \\
\hline 19 & 70.9 & 4.4 & $5 I \cdot 3$ \\
\hline 20 & 90.5 & 5.2 & 60.0 \\
\hline
\end{tabular}

The prescribed doses for small trees will be found too small, unless the trees are very low. The calculations are all based upon the sup. position that the trees are nearly spherical in chape; but in most cases it will be found that the trees of small dimensions have most of the branches raised fully four to five feet from the ground, thus leaving a large volume on the in. side of the tent unoccupied. Due allowance must be made when the hight of the tree is $s 0$ much greater than its diameter.

\section{Mode of Operating.}

Place the desired amount of acid in the acid receiver, then put the required amount of soda in a convenient vessel (* galion measure serves the purpose well) and add water to bring it to a this paste, stirring well to get rid of all the lumps, before the cyanide solution is added. Mix the cyanide solu. tion and the soda paste so that the undissolved soda will remain evenly distributed through 
the mixture. Pour into the cyanide receiver and allow it to run slowly and regularly upon the acid which has previously been run into the generator. As soon as the cyanide solution b sins to enter the generator, the blower should be turned slowly and continued until all the material is run in and violent action ceased. This usually takes a minute or so after the materials have united. Then fol. low with violent blowing for a minute or so and allow to rest until about 15 minutes from the beginning of the treatment, when, violent blowing is repeated for one minute. The time occupied in running in the mixture should be about as follows for the different sized trees:

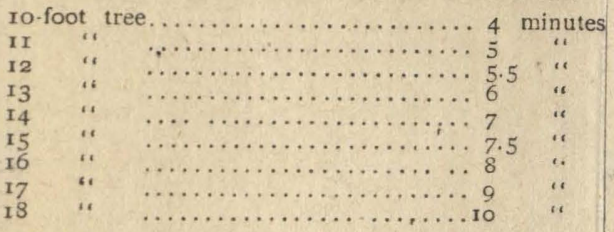

It is quite important that the time of injecting shall be closely observed, and should be length. exed rather than shortened. No time will be saved by hurrying this part of the treatment, for if run in too fast lumps will be formed which will take some time to be completely acted upon by the acid. If the time is slightly lengthened no serious results will follow. Some of the larg ast doses have been completely acted upon in less than 15 minutes, thus making it possible for a single generator to serve two tents when the prescribed time of exposure is adopted. It is advisable to continue the treatment of a eingle tree for about 30 minutes, although the time may be slightly. shortened when two tents are used.

\section{Injury to Foliage.}

It was plainly noticeable that under the influ. ence of the direct sunshine much more burning of the foliage took place. Trees, which were treated in the forenoon of hot days, were burned mostly upon the east side, and this in jury to the foliage appeared always upon the side of the tree which was exposed to the sun at the time of the treatment. The injury was undoubtedly done while the tent was upon the tree, and did not result from burning after the tent was removed.

Trees which were treated early in the morn ing or late in the afternoon remained perfectly unharmed. In one case the temperature in the shade was about $92^{\circ}$, while within and close to the sunny side of the tent the temperature reached $108110^{\circ}$.

This injury to the tree may be lessened some what by covering the frame with a cloth which will shade the tent; but it will be found more convenient to make the treatments with the gas in cooler seasons of the year, or in the cooler hours of the day. When injured by exposure to sun-heat the leaves drop off, but without injury to the green woody stems; fresh shoots have appeared in the course of three weeks after the treatment.

The prospects of effective treatment of scale insects by this method are quite promising. The gas is not only deadly to the insects but kills also the eggs, notwithstanding they are confined in the cottony cushion sac of the in. sect. The effect of the gas is equally deadly to the white as to the black and red scales.

Due attention should again be called to the extreme care which must be exercised in hand. ling the gas on account of its highly poisonous properties; this warning cannot be too strongly urged. But it has been shown by practical operation that no special danger threatens the op. erators if due care be taken.

The limits of a preliminary report preclude a detailed description of the apparatus used in the operation. It is recommended that those who are interested in the construction of a machine shall, if possible, make personal examina. tion of the working outfit at $S$ in Gabriel, and thus learn by actual observation the method of construction and operation. F. W. MORSE. Berkeley, Aug. 2\%, $188 \%$. 